\title{
Study of the Interaction between Gold Nanoparticles and Rose Bengal Fluorophores with Silica Spacers by Time-Resolved Fluorescence Spectroscopy
}

\author{
Hsing-Hui Lin and I-Chia Chen* \\ Department of Chemistry, National Tsing Hua University \\ Hsinchu, Taiwan 30013, Republic of China
}

E-mail: icchen@mx.nthu.edu.tw

Supporting Information: TEM images of $\mathrm{Au} @ \mathrm{SiO}_{2} \mathrm{NPs}$, emission spectra of $\mathrm{Au} @ \mathrm{SiO}_{2}-\mathrm{RB}, \log$ plots of rate constant vs. silica shell thickness, tables of silica shell thickness, surface plasmon band centers of $\mathrm{Au} @ \mathrm{SiO}_{2} \mathrm{NPs}$, and kinetic model analysis 


\section{Content}

\section{List of Figure Captions}

Figure S1. Representative TEM and SEM images of $\mathrm{Au} @ \mathrm{SiO}_{2} \mathrm{NPs}_{\text {(core diameter }=65}$ $\pm 4 \mathrm{~nm}$ ) with silica shell thickness: 5 (A), 10 (B), 18 (C), 35 (D), and $45 \mathrm{~nm}$ (E). The scale bar is $50 \mathrm{~nm}$.

Figure S2. Representative TEM and SEM images of $\mathrm{Au} @ \mathrm{SiO}_{2} \mathrm{NPs}$ (core diameter $=80$ $\pm 7 \mathrm{~nm}$ ) with silica shell thickness: 5 (A), 10 (B), 18 (C), 35 (D), and $45 \mathrm{~nm}$ (E). The scale bar is $50 \mathrm{~nm}$.

Figure S3. Representative TEM and SEM images of $\mathrm{Au} @ \mathrm{SiO}_{2} \mathrm{NPs}$ (core diameter $=100$ $\pm 7 \mathrm{~nm}$ ) with silica shell thickness: 5 (A), 10 (B), 18 (C), 35 (D), and $45 \mathrm{~nm}$ (E). The scale bar is $50 \mathrm{~nm}$.

Figure S4. TEM image of silica NPs. The size of silica NPs is $105 \pm 5 \mathrm{~nm}$ and the scale bar is $100 \mathrm{~nm}$.

Figure S5. Surface plasmon resonance band of $\mathrm{Au} @ \mathrm{SiO}_{2} \mathrm{NPs}$ with varied silica shell thickness. Gold core diameter in (A)-(D) is 45, 65, 80, and $100 \mathrm{~nm}$.

Figure S6. Fluorescence spectra of $\mathrm{Au} @ \mathrm{SiO}_{2}-\mathrm{RB}$ and silica-RB NPs with an excitation wavelength of $532 \mathrm{~nm}$ for various thicknesses of silica spacer. The diameters of gold NPs in (A)-(D) are 45, 65, 80, and $100 \mathrm{~nm}$, respectively. The sharp peaks are Raman bands of solvent isopropanol as shown in curve of (A).

Figure S7. Time-resolved decay profile and corresponding residuals. Blue circle is experimental data and red solid line shows the best fit. Only $5 \mathrm{~nm}$ and $10 \mathrm{~nm}$ thickness are shown. (A), (C), (E) and (G) are $5 \mathrm{~nm}$ thickness for 45, 65, 80 and $100 \mathrm{~nm}$ GNPs. (B), (D), (F) and (H) are $10 \mathrm{~nm}$ thickness for 45, 65, 80 and $100 \mathrm{~nm}$ GNPs.

Figure S8. Calculated quantum yield of $\mathrm{Au} @ \mathrm{SiO}_{2}-\mathrm{RB}$ for various thicknesses of silica spacer. The diameters of gold NPs in (A)-(D) are 45, 65, 80, and $100 \mathrm{~nm}$, 
respectively. When fluorophores are placed in vicinity of metal nanoparticles, the radiative decay rate of fluorophores is known to be increased, resulting in better quantum yield. Fluorescene quenching occurs when the excited fluorophores are coupled to the dark modes of GNPs. Because the energy transfer from fluorophores to dark modes of GNPs is dominant at shorter distances and it significantly decreases with distance, the quantum yield at 5 $\mathrm{nm}$ is the smallest and increases with distance. At large distances, the interaction between GNPs and fluorophores becomes weak, and the quantum yield drops to approach that in solution.

Figure S9. $\log \left(k_{E T, F l u o \rightarrow G N P(d a r k)}\right)$ vs. $\log ($ Separation). Solid lines are the best linear fits. The size of gold nanoparticle is 45 (triangle), 65 (circle), 80 (square), and 100 $\mathrm{nm}$ (star). The fitted slope shows $d^{-\mathrm{n}}$ dependence with $n=2.6 \pm 0.2,2.5 \pm 0.2$, $2.5 \pm 0.2,2.6 \pm 0.2$ for $45,65,80$, and $100 \mathrm{~nm}$ GNPs, respectively.

Figure S10. $\log \left(k_{E T, F l u o \rightarrow G N P(b r i g h t)}\right)$ vs. $\log ($ Separation). Solid lines are the best linear fits. The size of gold nanoparticle is 45 (triangle), 65 (circle), 80 (square), and 100 $\mathrm{nm}$ (star). The fitted slope shows $d^{-\mathrm{n}}$ dependence with $n=2.7 \pm 0.01,2.3 \pm$ $0.01,1.8 \pm 0.2,2.1 \pm 0.3$ for $45,65,80$, and $100 \mathrm{~nm}$ GNPs, respectively.

\section{List of Table Captions}

Table S1. Silica shell thickness of of $\mathrm{Au} @ \mathrm{SiO}_{2} \mathrm{NPs}$.

Table S2. Surface plasmon resonance band center of $\mathrm{Au} @ \mathrm{SiO}_{2} \mathrm{NPs}$ in isopropanol

Table S3. Best-fitted time constants and amplitudes of decay curves

\section{Excitation and Radiative Decay Rate Enhancement Factor}

Kinetic Model and Analysis 

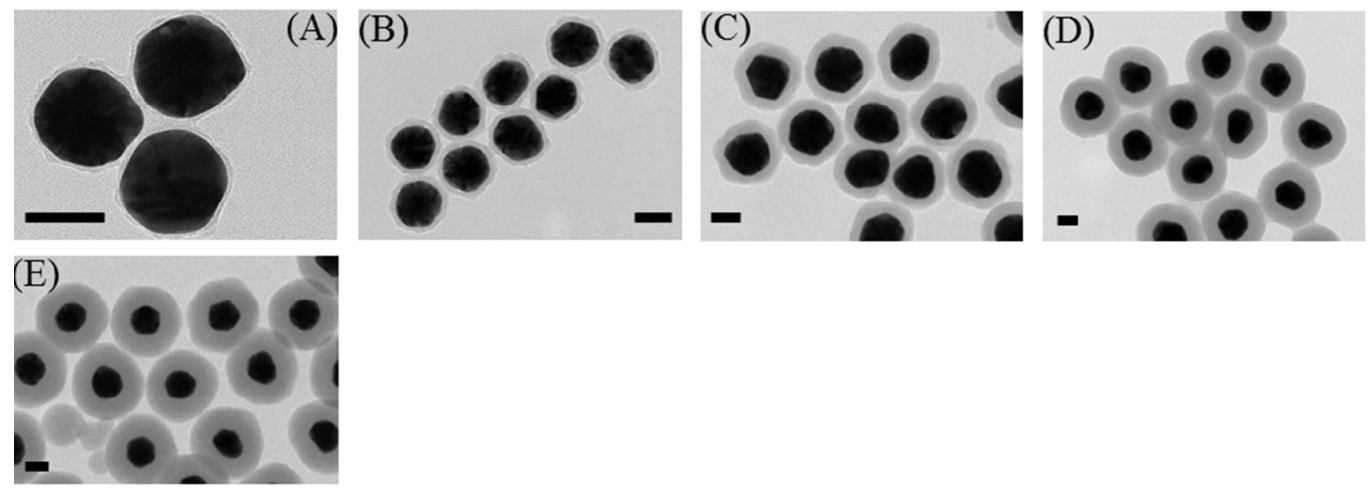

Figure S1. Representative TEM images of $\mathrm{Au} @ \mathrm{SiO}_{2} \mathrm{NPs}$ (core diameter $=65 \pm 4 \mathrm{~nm}$ ) with silica shell thickness: 5 (A), 10 (B), 18 (C), 35 (D), and $45 \mathrm{~nm}$ (E). The scale bar is $50 \mathrm{~nm}$.
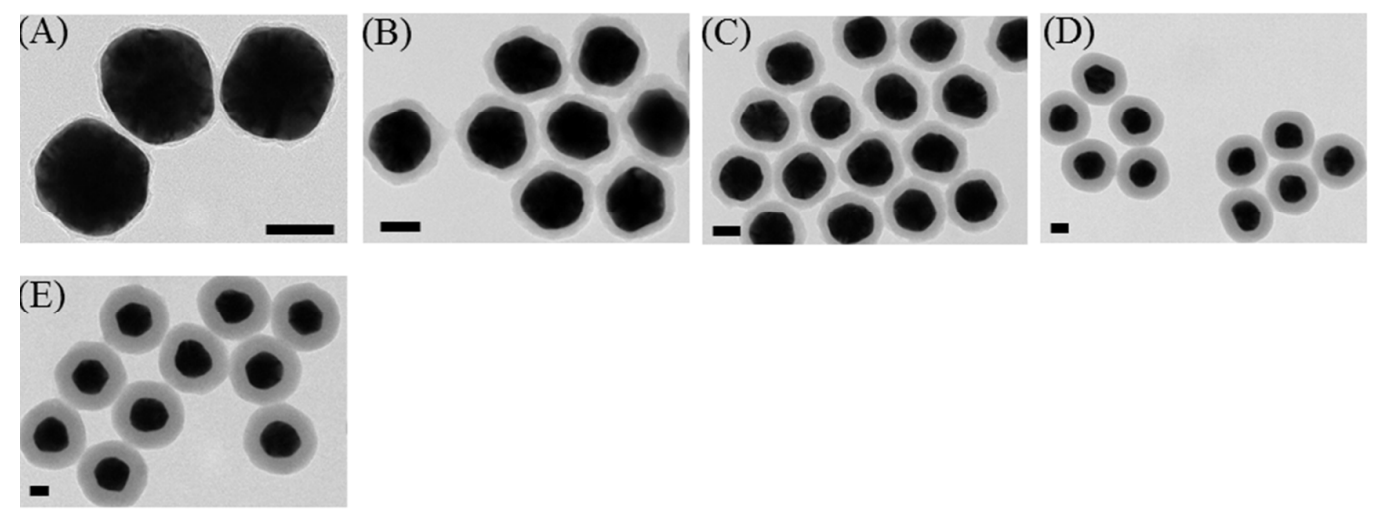

Figure S2. Representative TEM images of $\mathrm{Au} @ \mathrm{SiO}_{2} \mathrm{NPs}$ (core diameter $=80 \pm 7 \mathrm{~nm}$ ) with silica shell thickness: 5 (A), 10 (B), 18 (C), 35 (D), and $45 \mathrm{~nm}$ (E). The scale bar is $50 \mathrm{~nm}$.

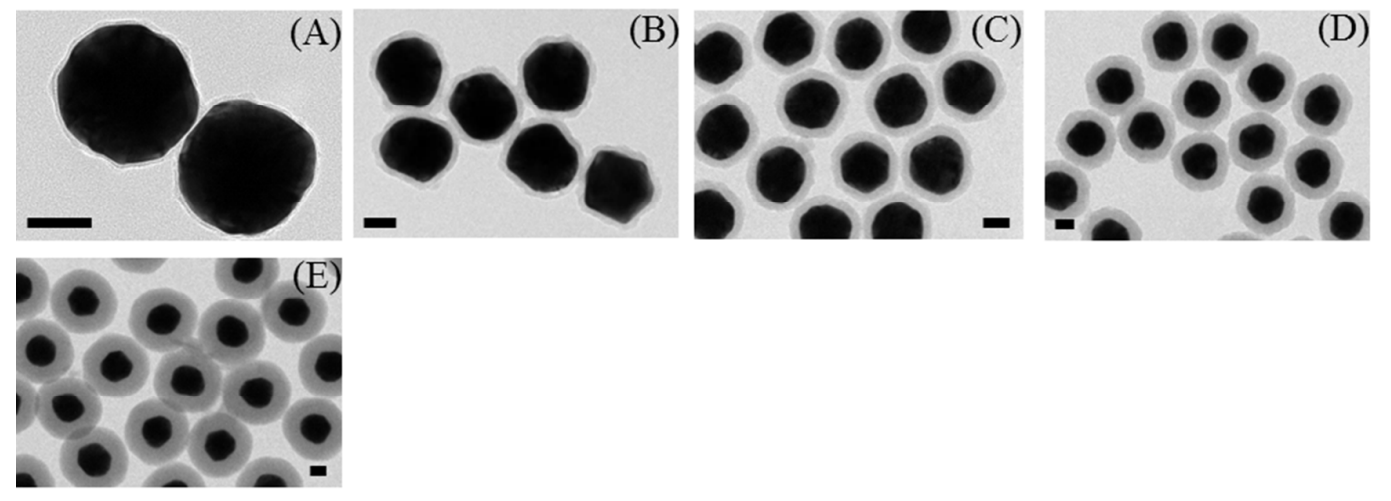

Figure S3. Representative TEM images of $\mathrm{Au} @ \mathrm{SiO}_{2} \mathrm{NPs}($ core diameter $=100 \pm 7 \mathrm{~nm})$ with silica shell thickness: 5 (A), 10 (B), 18 (C), 35 (D), and $45 \mathrm{~nm}$ (E). The scale bar is $50 \mathrm{~nm}$. 


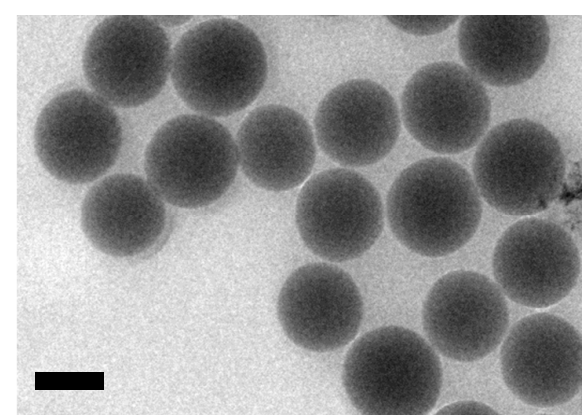

Figure S4. TEM image of silica NPs. The size of silica NPs is $105 \pm 5 \mathrm{~nm}$ and the scale bar is $100 \mathrm{~nm}$.
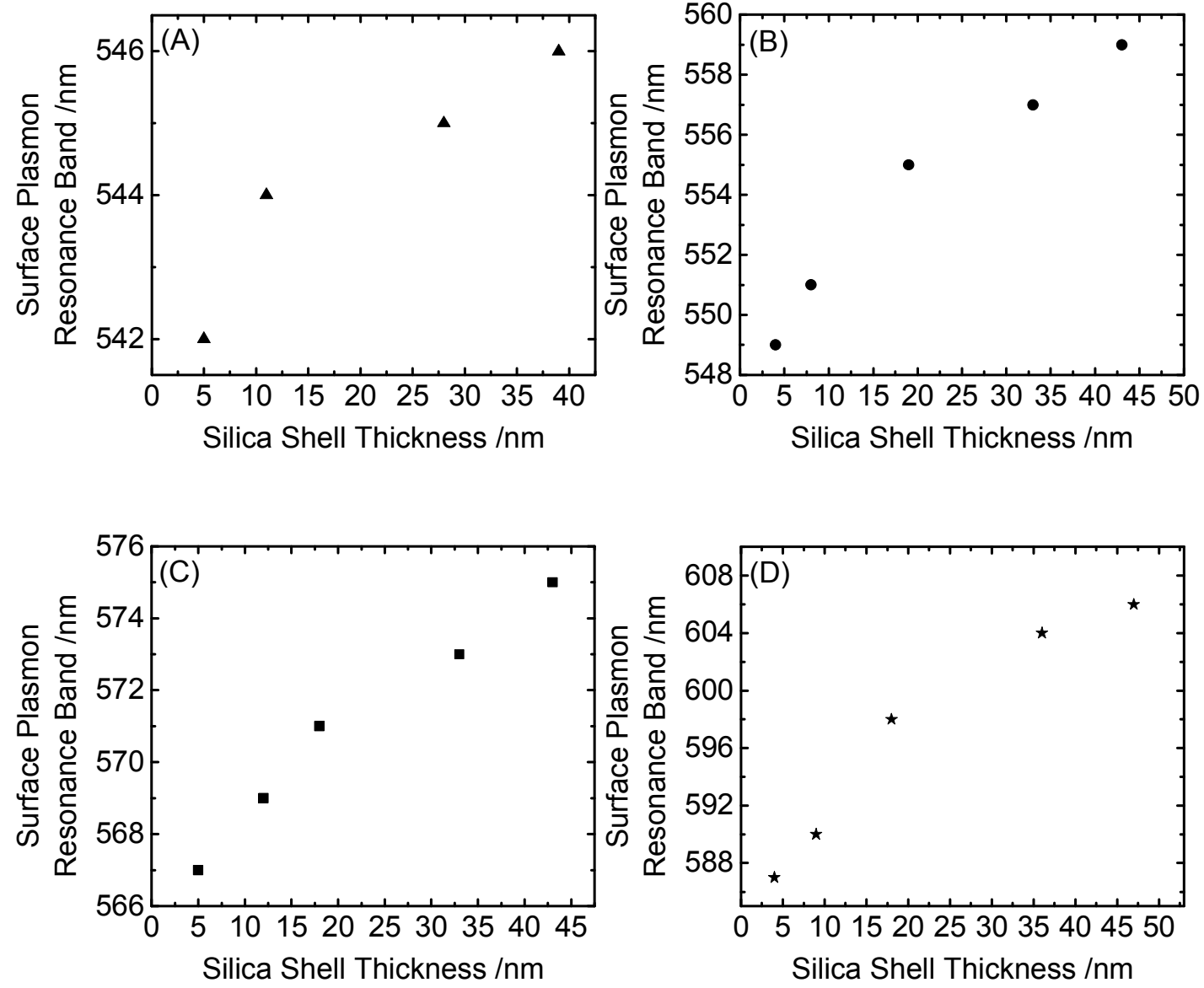

Figure S5. Surface plasmon resonance band of $\mathrm{Au} @ \mathrm{SiO}_{2} \mathrm{NPs}$ with varied silica shell thickness. Gold core diameter in (A)-(D) is 45, 65, 80, and $100 \mathrm{~nm}$. 

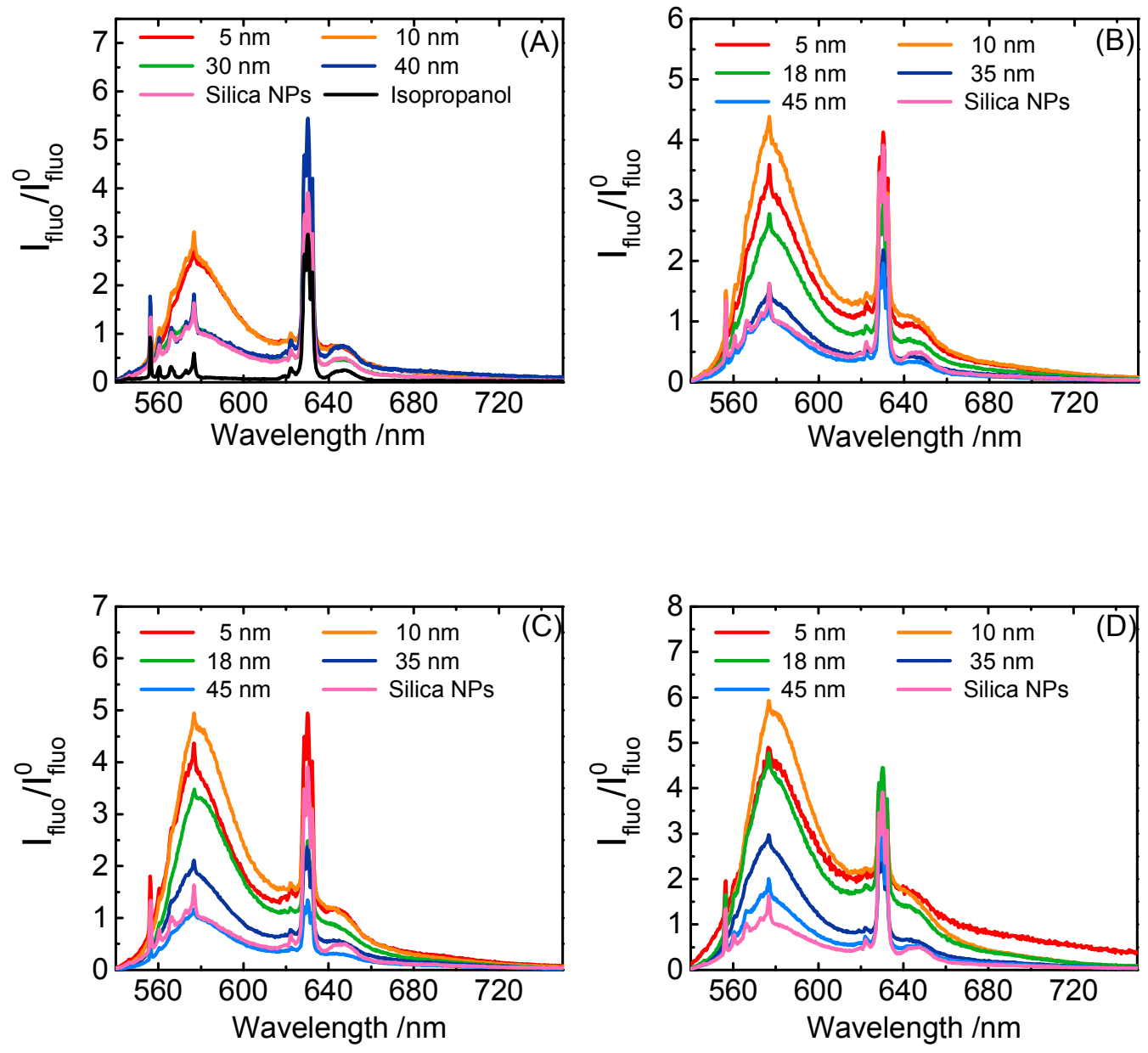

Figure S6. Fluorescence spectra of $\mathrm{Au} @ \mathrm{SiO}_{2}-\mathrm{RB}$ and silica-RB NPs with an excitation wavelength of $532 \mathrm{~nm}$ for various thicknesses of silica spacer. The diameters of gold NPs in (A)-(D) are 45, 65, 80, and $100 \mathrm{~nm}$, respectively. The sharp peaks are Raman bands of solvent isopropanol as shown in curve of (A). 

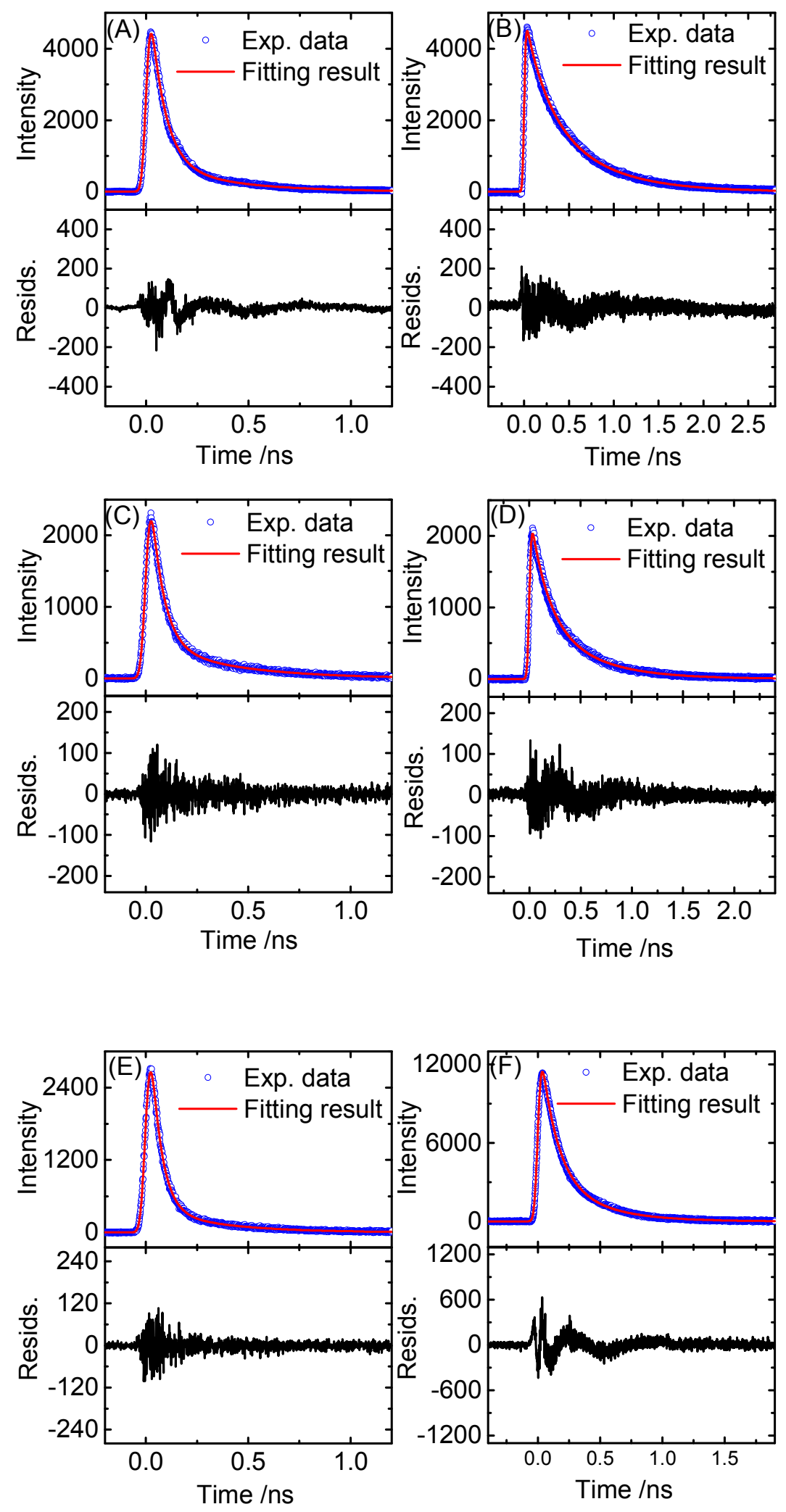

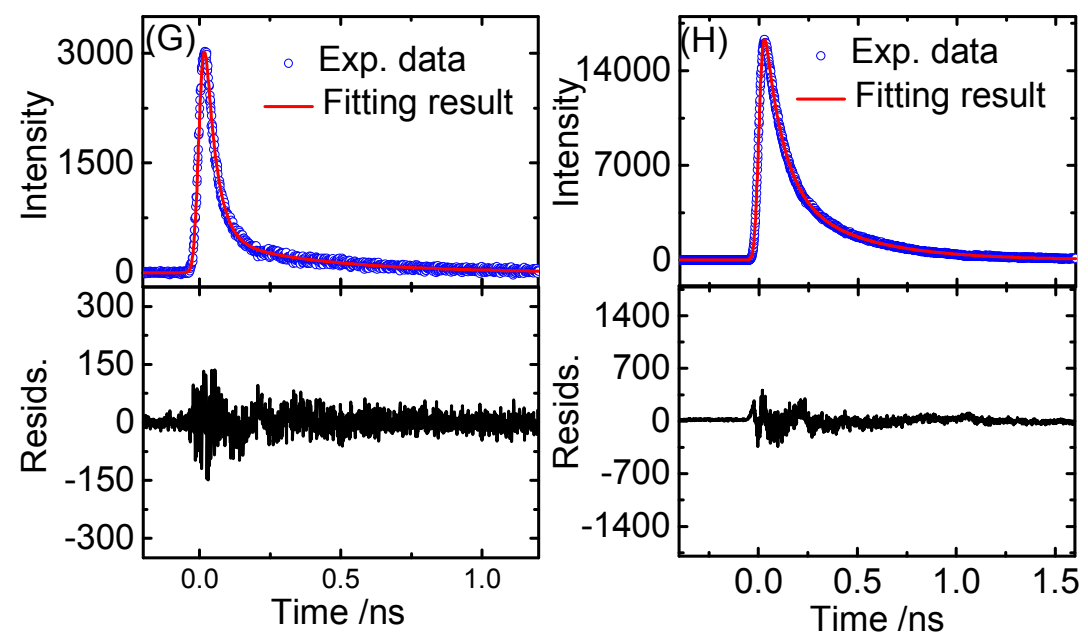

Figure S7. Time-resolved decay profile and corresponding residuals. Blue circle is experimental data and red solid line shows the best fit. Only $5 \mathrm{~nm}$ and $10 \mathrm{~nm}$ thickness are shown. (A), (C), (E) and (G) are $5 \mathrm{~nm}$ thickness for 45, 65, 80 and $100 \mathrm{~nm}$ GNPs. (B), (D), (F) and (H) are $10 \mathrm{~nm}$ thickness for 45, 65, 80 and $100 \mathrm{~nm}$ GNPs.
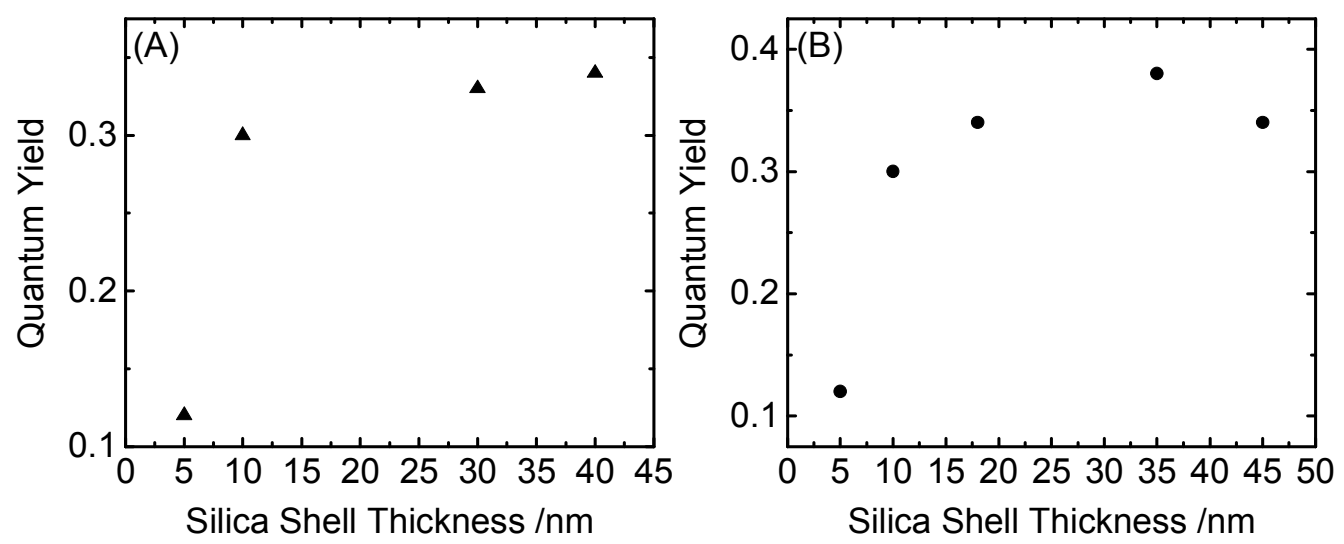

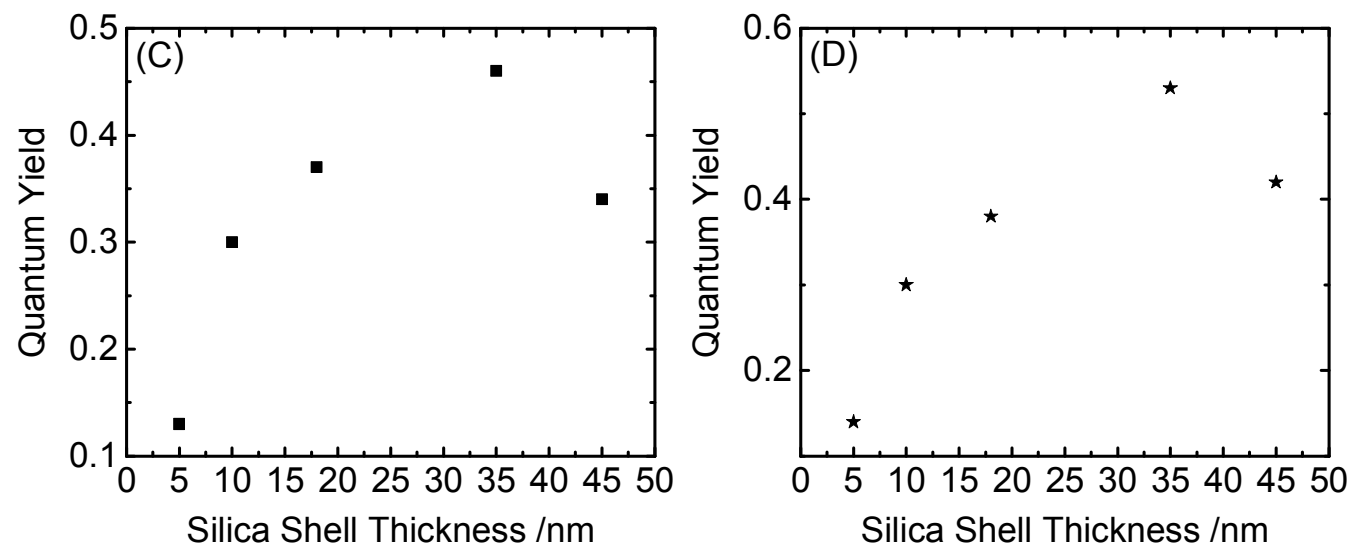

Figure S8. Calculated quantum yield of $\mathrm{Au} @ \mathrm{SiO}_{2}-\mathrm{RB}$ for various thicknesses of silica spacer. The diameters of gold NPs in (A)-(D) are 45, 65, 80, and $100 \mathrm{~nm}$, respectively. When fluorophores are placed in vicinity of metal nanoparticles, the radiative decay rate of fluorophores is known to be increased, resulting in better quantum yield. Fluorescene quenching occurs when the excited fluorophores are coupled to the dark modes of GNPs. Because the energy transfer from fluorophores to dark modes of GNPs is dominant at shorter distances and it significantly decreases with distance, the quantum yield at $5 \mathrm{~nm}$ is the smallest and increases with distance. At large distances, the interaction between GNPs and fluorophores becomes weak, and the quantum yield drops to approach that in solution. 


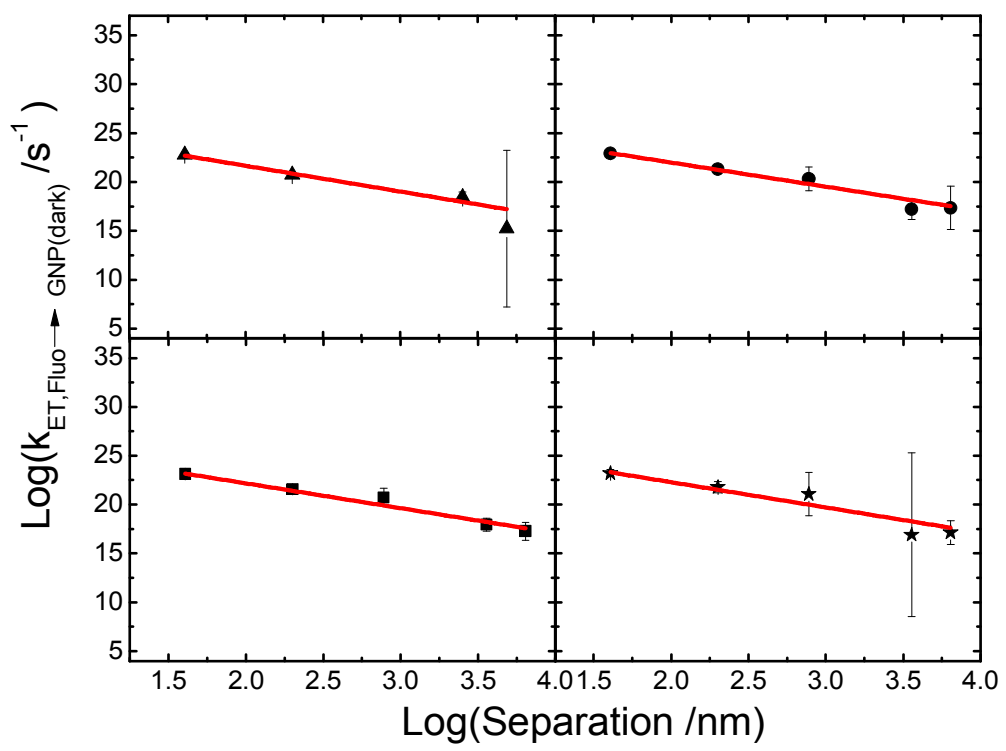

Figure S9. $\log \left(k_{E T, F l u o \rightarrow G N P(d a r k)}\right)$ vs. $\log ($ Separation). Solid lines are the best linear fits. The size of gold nanoparticle is 45 (triangle), 65 (circle), 80 (square), and $100 \mathrm{~nm}$ (star). The fitted slope shows $d^{-\mathrm{n}}$ dependence with $n=2.6 \pm 0.2,2.5 \pm 0.2,2.5 \pm 0.2,2.6 \pm 0.2$ for $45,65,80$, and $100 \mathrm{~nm}$ GNPs, respectively. 


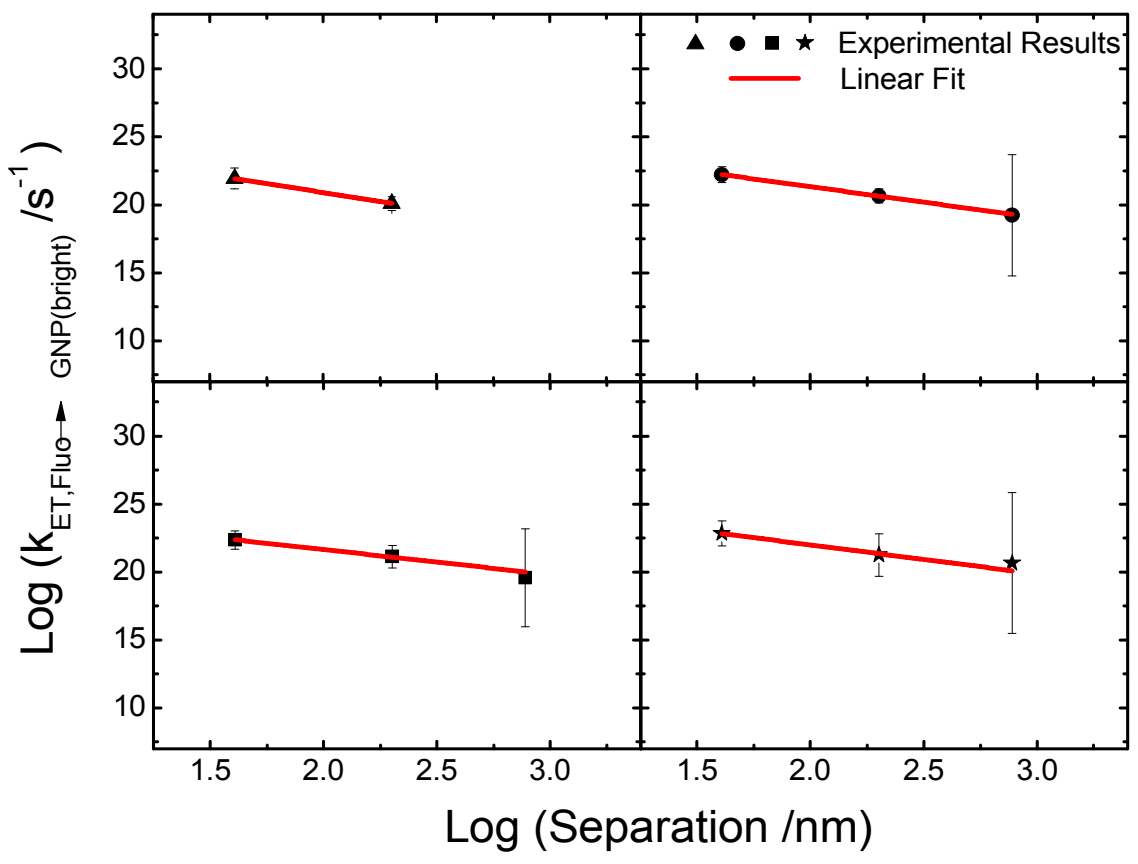

Figure S10. $\log \left(k_{E T, F l u o \rightarrow G N P(b r i g h t)}\right)$ vs. $\log ($ Separation). Solid lines are the best linear fits. The size of gold nanoparticle is 45 (triangle), 65 (circle), 80 (square), and $100 \mathrm{~nm}$ (star). The fitted slope shows $d^{-\mathrm{n}}$ dependence with $n=2.7 \pm 0.01,2.3 \pm 0.01,1.8 \pm 0.2,2.1 \pm 0.3$ for $45,65,80$, and $100 \mathrm{~nm}$ GNPs, respectively. 
Table S1. Silica shell thickness of Au@SiO2 NPs

\begin{tabular}{cccccc}
\hline GNPs $(\mathrm{nm})$ & Shell \#1(nm) & Shell \#2(nm) & Shell \#3(nm) & Shell \#4(nm) & Shell \#5(nm) \\
\hline $45 \pm 3$ & $5 \pm 1$ & $11 \pm 1$ & $28 \pm 3$ & $42 \pm 3$ & \\
$65 \pm 3$ & $4 \pm 1$ & $8 \pm 2$ & $19 \pm 2$ & $33 \pm 2$ & $43 \pm 3$ \\
$80 \pm 5$ & $5 \pm 1$ & $12 \pm 2$ & $18 \pm 2$ & $33 \pm 4$ & $43 \pm 4$ \\
$100 \pm 7$ & $4 \pm 1$ & $9 \pm 1$ & $18 \pm 2$ & $36 \pm 5$ & $47 \pm 4$ \\
\hline
\end{tabular}

Table S2. Surface plasmon resonance band center of Au@SiO2 NPs in isopropanol GNPs $(\mathrm{nm}) \quad$ Shell \#1(nm) Shell \#2(nm) Shell \#3(nm) Shell \#4(nm) Shell \#5(nm)

\begin{tabular}{cccccc}
$45 \pm 3$ & 542 & 544 & 545 & 546 & \\
$65 \pm 3$ & 549 & 551 & 555 & 557 & 559 \\
$80 \pm 5$ & 567 & 569 & 571 & 573 & 575 \\
$100 \pm 7$ & 587 & 590 & 598 & 604 & 606 \\
\hline
\end{tabular}

Table S3. The best-fitted time constants and amplitudes of emission decay curves

\begin{tabular}{rcccc}
\hline $45 \mathrm{~nm}$ & $\tau_{1} / \mathrm{ns}$ & $\tau_{2} / \mathrm{ns}$ & $\mathrm{A}_{1}$ & $\mathrm{~A}_{2}$ \\
\hline $5 \mathrm{~nm}$ & $0.07 \pm 0.01$ & $0.36 \pm 0.02$ & $0.88 \pm 0.02$ & $0.12 \pm 0.03$ \\
$10 \mathrm{~nm}$ & $0.24 \pm 0.01$ & $0.63 \pm 0.01$ & $0.43 \pm 0.02$ & $0.57 \pm 0.03$ \\
$30 \mathrm{~nm}$ & & $1.1 \pm 0.05$ & & \\
$40 \mathrm{~nm}$ & & $1.23 \pm 0.02$ & & $\mathrm{~A}_{2}$ \\
\hline $65 \mathrm{~nm}$ & $\tau_{1} / \mathrm{ns}$ & $\tau_{2} / \mathrm{ns}$ & $\mathrm{A}_{1}$ & $0.12 \pm 0.04$ \\
\hline $5 \mathrm{~nm}$ & $0.06 \pm 0.01$ & $0.35 \pm 0.03$ & $0.88 \pm 0.03$ & $0.44 \pm 0.03$ \\
$10 \mathrm{~nm}$ & $0.17 \pm 0.01$ & $0.47 \pm 0.04$ & $0.56 \pm 0.04$ & $0.55 \pm 0.2$ \\
$18 \mathrm{~nm}$ & $0.36 \pm 0.03$ & $0.73 \pm 0.06$ & $0.45 \pm 0.2$ & \\
$35 \mathrm{~nm}$ & & $1.17 \pm 0.01$ & & $\mathrm{~A}_{2}$ \\
$45 \mathrm{~nm}$ & & $1.23 \pm 0.1$ & & $0.39 \pm 0.06$ \\
\hline $80 \mathrm{~nm}$ & $\tau_{1} / \mathrm{ns}$ & $\tau_{2} / \mathrm{ns}$ & $\mathrm{A}_{1}$ & \\
\hline $5 \mathrm{~nm}$ & $0.05 \pm 0.01$ & $0.33 \pm 0.01$ & $0.91 \pm 0.03$ & $0.46 \pm 0.13$ \\
$10 \mathrm{~nm}$ & $0.13 \pm 0.01$ & $0.42 \pm 0.07$ & $0.61 \pm 0.1$ & \\
$18 \mathrm{~nm}$ & $0.28 \pm 0.05$ & $0.57 \pm 0.03$ & $0.54 \pm 0.15$ & $\mathrm{~A}_{2}$ \\
$35 \mathrm{~nm}$ & & $0.96 \pm 0.02$ & & $0.09 \pm 0.01$ \\
$45 \mathrm{~nm}$ & & $1.24 \pm 0.01$ & & $0.32 \pm 0.02$ \\
$100 \mathrm{~nm}$ & $\tau_{1} / \mathrm{ns}$ & $\tau_{2} / \mathrm{ns}$ & $\mathrm{A}_{1}$ & \\
\hline $5 \mathrm{~nm}$ & $0.04 \pm 0.01$ & $0.35 \pm 0.03$ & $0.91 \pm 0.01$ & \\
$10 \mathrm{~nm}$ & $0.12 \pm 0.03$ & $0.4 \pm 0.03$ & $0.68 \pm 0.05$ &
\end{tabular}




\section{Excitation and Radiative Decay Rate Enhancement Factor}

The excitation and radiative decay rate enhancement factor are calculated following the equations given by Guzatov et al. ${ }^{1}$ The normal and tangential components of excitation enhancement factor are calculated separately

$$
\begin{aligned}
& \left(\frac{I_{e x}}{I_{e x}^{0}}\right)_{n o r m}=\left|1+2\left(\frac{\varepsilon_{m}\left(\omega_{e x c}\right)-\varepsilon_{s}}{\varepsilon_{m}\left(\omega_{e x c}\right)+2 \varepsilon_{s}}\right)\left(\frac{a}{r}\right)^{3}\right|^{2} \\
& \left(\frac{I_{e x}}{I_{e x}^{0}}\right)_{\text {tang }}=\left|1-\left(\frac{\varepsilon_{m}\left(\omega_{e x c}\right)-\varepsilon_{s}}{\varepsilon_{m}\left(\omega_{e x c}\right)+2 \varepsilon_{s}}\right)\left(\frac{a}{r}\right)^{3}\right|^{2}
\end{aligned}
$$

where $\omega_{e x c}$ is the angular frequency of excitation light, $r$ is the radius vector from the metal nanoparticle center to fluorophore, $\varepsilon_{m}$ and $\varepsilon_{s}$ are the complex dielectric constants of metal NP and surrounding medium, respectively. Dielectric constant $\varepsilon_{\mathrm{m}}$ for $\mathrm{Au} @ \mathrm{SiO}_{2}$ is calculated according to the equations given by Khlebtsov et al. ${ }^{2}$ Assuming isotropic condition, the averaged excitation enhancement factor is

$$
\left\langle\frac{I_{e x}}{I_{e x}^{0}}\right\rangle_{\text {ave }}=\frac{1}{3}\left(\frac{I_{e x}}{I_{e x}^{0}}\right)_{n o r m}+\frac{2}{3}\left(\frac{I_{e x}}{I_{e x}^{0}}\right)_{\text {tang }}
$$

For radiative decay rate enhancement factor, the normal and tangential components of the radial orientation of a molecule dipole moment with respect to the metal nanoparticle surface are calculated separately

$$
\begin{aligned}
& \left(\frac{k_{r, m}}{k_{r}}\right)_{n o r m}=\left|1+2\left(\frac{\varepsilon_{m}\left(\omega_{e m}\right)-\varepsilon_{s}}{\varepsilon_{m}\left(\omega_{e m}\right)+2 \varepsilon_{s}}\right)\left(\frac{a}{r}\right)^{3}\right|^{2} \\
& \left(\frac{k_{r, m}}{k_{r}}\right)_{\tan g}=\left|1-\left(\frac{\varepsilon_{m}\left(\omega_{e m}\right)-\varepsilon_{s}}{\varepsilon_{m}\left(\omega_{e m}\right)+2 \varepsilon_{s}}\right)\left(\frac{a}{r}\right)^{3}\right|^{2}
\end{aligned}
$$


where $\omega_{e m}$ is the angular frequency of emission. The enhancement factor of averaged isotropic radiative decay rate is obtained to be

$$
\left\langle\frac{k_{r, m}}{k_{r}}\right\rangle_{\text {ave }}=\frac{1}{3}\left(\frac{k_{r, m}}{k_{r}}\right)_{n o r m}+\frac{2}{3}\left(\frac{k_{r, m}}{k_{r}}\right)_{\text {tan } g}
$$

\section{Kinetic Model and Analysis}

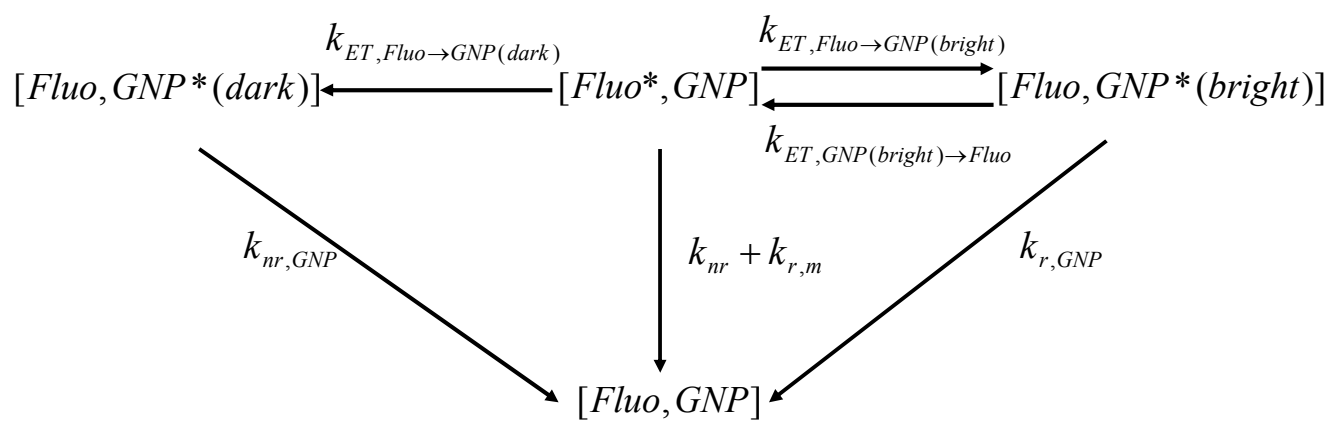

Based on the kinetic model proposed above, the fluorescence intensity as a function of time can be written as

$I(t)=\frac{\left[\text { Fluo }^{*}, G N P\right]_{0}}{\beta-\alpha}\left[(\gamma-\alpha) e^{-\alpha t}-(\gamma-\beta) e^{-\beta t}\right]$ where

$\alpha+\beta=k_{n r}+k_{r, m}+k_{E T, F l u o \rightarrow G N P(b r i g h t)}+k_{E T, F l u o \rightarrow G N P(\text { dark })}+k_{E T, G N P(\text { bright }) \rightarrow F l u o}+k_{r, G N P}$,

$\alpha \times \beta=\left(k_{n r}+k_{r, m}+k_{E T, F l u o \rightarrow G N P(\text { dark })}\right) \times\left(k_{E T, G N P(b r i g h t) \rightarrow F l u o}+k_{r, G N P}\right)+k_{E T, F l u o \rightarrow G N P(b r i g h t)} \times k_{r, G N P}$,

and $\gamma=k_{E T, F l u o \rightarrow G N P(b r i g h t)}+k_{E T, G N P(\text { bright }) \rightarrow F l u o}+k_{r, G N P}$.

Fitted time constants $\left(\tau_{1}\right.$ and $\left.\tau_{2}\right)$ and respective ratio of amplitudes $\left(A_{1}\right.$ and $\left.A_{2}\right)$ can be expressed as

$$
\tau_{1}=\frac{1}{\alpha}
$$




$$
\begin{aligned}
\tau_{1} & =\frac{1}{\beta} \\
\frac{A_{1}}{A_{2}} & =\frac{\alpha-\gamma}{\gamma-\beta}
\end{aligned}
$$

We let $k_{1}=k_{r, m}+k_{E T, F l u o \rightarrow G N P(d a r k)}+k_{n r}$ and $k_{2}=k_{E T, F l u o \rightarrow G N P(b r i g h t)}+k_{E T, G N P \rightarrow F l u o}+k_{r, G N P}$.

Case $k_{r, G N P} \gg k_{E T, G N P(b r i g h t) \rightarrow F l u o}$

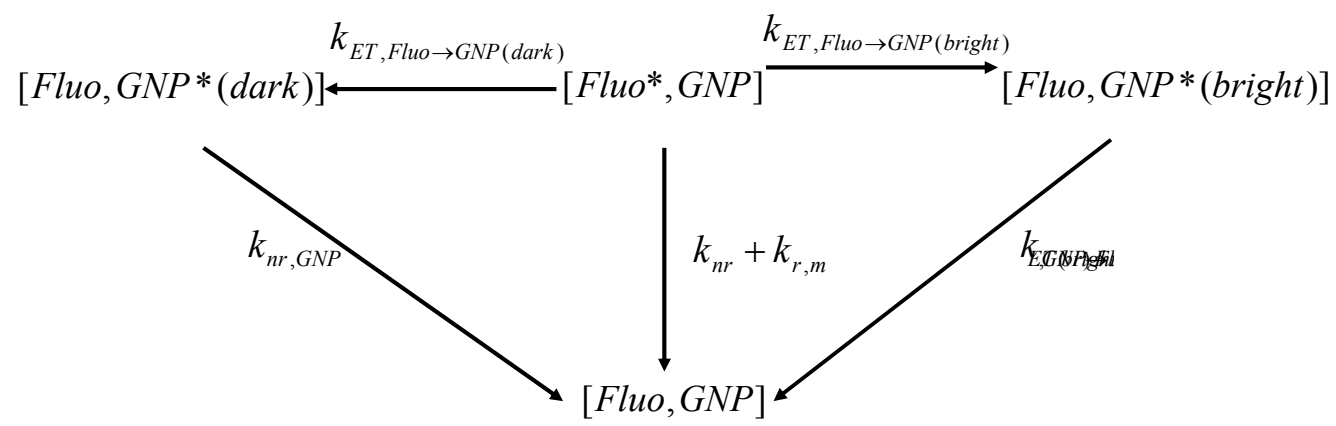

The fluorescence intensity as a function of time can be written as

$$
I(t)=\frac{[\text { Fluo }, G N P]_{0}}{k_{1}+k_{E T, R B \rightarrow G N P(b r i g h t)}-k_{r, G N P}} \times\left[\left(k_{1}-k_{r, G N P}\right) e^{-\left(k_{1}+k_{E T, F h u \rightarrow G N P(b r i g h t)}\right) t}+k_{E T, F l u o \rightarrow G N P(b r i g h t)} e^{-k_{r, G N P} t}\right]
$$

where $k_{1}=k_{n r}+k_{r, m}+k_{E T, F \text { Iuo } \rightarrow G N P(d a r k)}$. The fitted time constants and respective ratio of amplitudes can be expressed as

$$
\begin{gathered}
\frac{1}{\tau_{1}}=k_{1}+k_{E T, F l u o \rightarrow G N P(b r i g h t)} \\
\frac{1}{\tau_{2}}=k_{r, G N P} \\
\frac{A_{1}}{A_{2}}=\frac{k_{1}-k_{r, G N P}}{k_{E T, F l u o \rightarrow G N P(b r i g h t)}}
\end{gathered}
$$


We define $k_{1}^{\prime}=k_{r, m}+k_{E T, F l u o \rightarrow G N P(d a r k)}, k_{E T, F l u o \rightarrow G N P(b r i g h t)}$, and $k_{r, G N P}$. The quantum yield obtained using the steady-state fluorescence intensity is written as

$$
\begin{aligned}
& Q=Q_{F l u o}+Q_{G N P} \cong \frac{\int_{0}^{\infty} k_{r, m}\left[\text { Fluo }^{*}, G N P\right] d t}{\left[\text { Fluo }^{*}, G N P\right]_{0}}+\frac{\int_{0}^{\infty} k_{r, G N P}\left[\text { Fluo }, G N P^{*}(\text { bright })\right] d t}{\left[\text { Fluo }^{*}, G N P\right]_{0}} \\
& Q_{\text {Fluo }}=\frac{\int_{0}^{\infty} k_{r, m}\left[\text { Fluo }^{*}, G N P\right] d t}{[\text { Fluo }, G N P]_{0}}=\frac{k_{r, m}}{k_{n r}+k_{r, m}+k_{E T, F l u o \rightarrow G N P(d a r k)}+k_{E T, F l u o \rightarrow G N P(b r i g h t)}} \\
& Q_{G N P}=\frac{\int_{0}^{\infty} k_{r, G N P}\left[\text { Fluo }, G N P^{*}(\text { bright })\right] d t}{[\text { Fluo }, G N P]_{0}}=\frac{k_{r, G N P} k_{E T, F l u o \rightarrow G N P(b r i g h t)}}{k_{n r}+k_{r, m}+k_{E T, F l u o \rightarrow G N P(\text { bright })}+k_{E T, F l u o \rightarrow G N P(\text { dark })}-k_{r, G N P}} \times \\
& {\left[\frac{1}{k_{r, G N P}}-\frac{1}{k_{n r}+k_{r, m}+k_{E T, F l u o \rightarrow G N P(b r i g h t)}+k_{E T, F l u o \rightarrow G N P(\text { dark })}}\right]}
\end{aligned}
$$

Then, $k_{r, m}$ could be calculated as

$$
k_{r, m}=\left(Q-Q_{G N P}\right) \times\left(k_{n r}+k_{r, m}+k_{E T, F l u o \rightarrow G N P(d a r k)}+k_{E T, F h u \rightarrow G N P(b r i g h t)}\right)
$$

from the known value of $k_{n r}$. In this case $k_{r, G N P}>>k_{E T, G N P(b r i g h t) \rightarrow F l u o}$, energy transfer from the bright mode of GNP to fluorophores is neglected. In some experimental conditions, the calculated quantum yield of radiating bright mode of GNP becomes overestimated, resulting in smaller quantum yield of radiation for RB and smaller $k_{r, m}$ than $k_{\mathrm{r}}$. This disagrees with the experimental finding that $k_{r, m}$ must be greater than $k_{\mathrm{r} .}$ As a result, the energy transfer from bright mode of GNP to fluorophores can not be ignored. 
Case $k_{E T, G N P(b r i g h t) \rightarrow F l u o}>k_{r, G N P}$

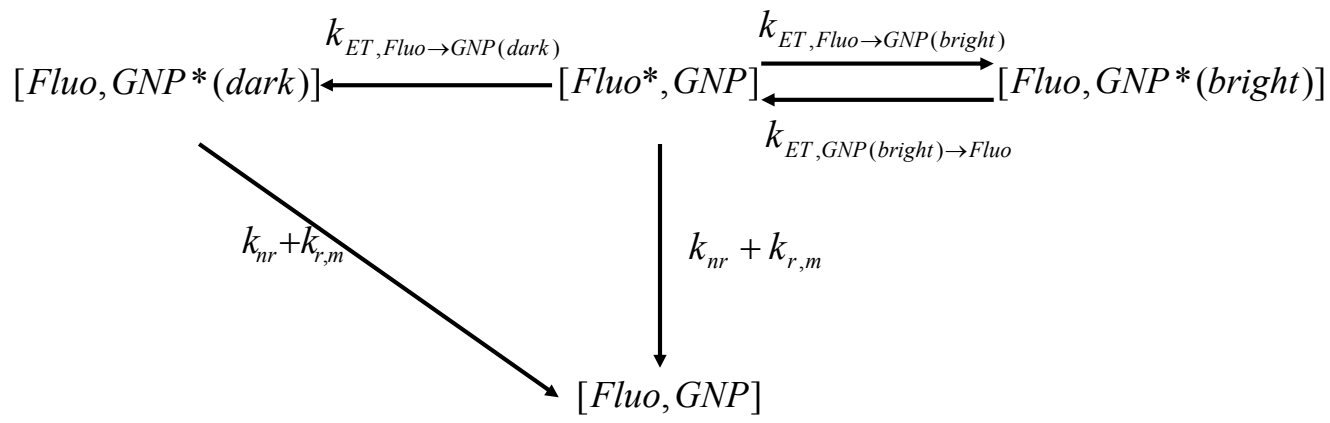

The fluorescence intensity as a function of time can be written as

$$
I(t)=\frac{\left[F l u o^{*}, G N P\right]_{0}}{b^{\prime}-a^{\prime}}\left[\left(c^{\prime}-a^{\prime}\right) e^{-a^{\prime} t}-\left(c^{\prime}-b^{\prime}\right) e^{-b^{\prime} t}\right]
$$

where $\quad a^{\prime}+b^{\prime}=k_{n r}+k_{r, m}+k_{E T, F l u o \rightarrow G N P(b r i g h t)}+k_{E T, F l u o \rightarrow G N P(d a r k)}+k_{E T, G N P(b r i g h t) \rightarrow \text { Fluo }}$, $a^{\prime} \times b^{\prime}=\left(k_{n r}+k_{r, m}+k_{E T, F \text { Fuo } \rightarrow G N P(d a r k)}\right) \times k_{E T, G N P(\text { bright }) \rightarrow F l u o}$, and $c^{\prime}=k_{E T, G N P(\text { bright }) \rightarrow F l u o}$. The fitted time constants $\left(\tau_{1}\right.$ and $\left.\tau_{2}\right)$ and respective ratio of amplitude $\left(A_{1}\right.$ and $\left.A_{2}\right)$ can be expressed as

$$
\begin{gathered}
\frac{1}{\tau_{1}}=a \\
\frac{1}{\tau_{2}}=b \\
\frac{A_{1}}{A_{2}}=\frac{a-c}{c-b}
\end{gathered}
$$

Then, $k_{E T, G N P(b r i g h t) \rightarrow F l u o}, k_{E T, F l u o \rightarrow G N P(b r i g h t)}$, and $k_{1}^{\prime}=k_{r, m}+k_{E T, F l u o \rightarrow G N P(d a r k)}$ can be obtained as follows:

$$
k_{E T, G N P(b r i g h t) \rightarrow F l u o}=\frac{A_{1} b+A_{2} a}{(a+b)}
$$




$$
\begin{gathered}
k_{1}^{\prime}=\frac{a \times b}{k_{E T, G N P(b r i g h t) \rightarrow F l u o}}-k_{n r} \\
k_{E T, F l u o \rightarrow G N P(b r i g h t)}=a+b-k_{1}^{\prime}-k_{n r}-k_{E T, G N P(\text { bright }) \text { Fluo }}
\end{gathered}
$$

\section{References}

1. Guzatov, D. V.; Vaschenko, S. V.; Stankevich, V. V.; Lunevich, A. Y.; Glukhov, Y. F.; Gaponenko, S. V. Plasmonic Enhancement of Molecular Fluorescence near Silver Nanoparticles: Theory, Modeling, and Experiment. J. Phys. Chem. C 2012, 116, 10723-10733.

2. Khlebtsov, N. G.; Khlebtsov, B. N. Optical polarizability of metal nanoparticles and their biospecific conjugates. Proc. of SPIE 2006, 6164, 616405. 